\title{
Characterization of Meta-Kaolin based Geopolymers Produced by Pre-Curing Process
}

\author{
${ }^{1}$ Byeongguk Kang, ${ }^{2}$ Kangduk Kim and ${ }^{3}$ Seunggu Kang \\ ${ }^{1}$ Department of Advanced Materials-Science and Engineering, Kyonggi University, Suwon, \\ 106-203, 90 Supung-ro, Suji-gu, Yongin-si, Gyeonggi-do, Republic of Korea \\ ${ }^{2}$ Department of Advanced Materials-Science and Engineering, Kyonggi University, Suwon, \\ 103-103, 33 Geumdang-ro, 39 Beon-gil, Jangan-gu, Suwon-si, Gyeonggi-do, Republic of Korea \\ ${ }^{3}$ Department of Advanced Materials-Science and Engineering, Kyonggi University, Suwon, \\ 211-302, 221 Seolleung-ro, Gangnam-gu, Seoul, Republic of Korea
}

\begin{abstract}
This study was conducted to research the effect of the pre-curing process on the compressive strength of meta-kaolin-based-geopolymers. Pre-curing is a process in which the green geopolymer is left at room temperature for a certain period of time prior to high-temperature curing and it is known to be effective for increasing the strength of the geopolymers. In this experiment, the compressive strength of geopolymers was measured according to various pre-curing conditions. Various properties of geopolymers fabricated with a pre-curing process were analyzed using UTM, XRD, SEM, FT-IR and a Gilmore needle tester. It was found that pre-curing was effective in improving the compressive strength of meta-kaolin-based-geopolymers. For example, the specimens prepared by pre-curing for 6 days during a total curing process of 7 days showed the highest compressive strength and the specimens prepared by pre-curing for 13 days during a total curing process of 28 days showed the highest compressive strength, $76.3 \mathrm{MPa}$ which is 2.4 times higher than that of specimen made without pre-curing process. Several crystal phases such as zeolite, cancrinite and Calcium-Aluminium-Silicate-Hydrate (denoted as C-A-S-H) were found in the geopolymer gel and the compressive strength of the geopolymer increased with pre-curing time and amount of cancrinite and C-A-S-H phases.
\end{abstract}

$\underline{\text { Key words: Geopolymer, meta-kaolin, pre-curing, compressive strength, strength, pre-curing, cancrinite }}$

\section{INTRODUCTION}

Since, the 2000's environmental problems caused by greenhouse gases have become a major focus of developed countries and research to reduce emissions of Carbon dioxide $\left(\mathrm{CO}_{2}\right)$, the dominant greenhouse gas is actively being carried out. Cement, a typical building material, produces about 0.4-1.0 tons of carbon dioxide for 1 ton of cement produced and accounts for about $5-7 \%$ of the total carbon dioxide generated by humans (Anonymous, 2002a, b; Pullagujju, 2015). Therefore, even though cement has been widely used for construction and civil engineering for hundreds of years due to the low cost of raw materials, research has been actively conducted to develop a new environmentally friendly inorganic binder as a substitute for cement.

Geopolymers are one of the potential substitutes for cement and researchers have argued that they can reduce the amount of carbon dioxide emitted from cement by $80 \%$. Davidovits (1994), a French materials scientist, first found this material and named it 'geopolymer' because the raw material is an alumino-silicate system which has abundant constituents in the soil and its structure resembles that of a polymer.

Geopolymers are made by an activation reaction using an alkali solution that is polymerized at low temperature to form an inorganic polymer and frequently various zeolite phases are incorporated in the geopolymer by a high temperature curing process (Mounica, 2015; Davidovits, 1998, 1991; Bhavana, 2015). Various raw materials are available for making geopolymers, including material containing large amounts of alumino-silicate materials such as byproducts or waste, fly ash and blast furnace slag as well as meta-kaolin (Nadella, 2016; Choi et al., 2016; Jeon and Song, 2011; Cho et al., 2014; Dubey and Tomar, 2017; Kim and Kang, 2014; Joo et al., 2012; Zhao et al., 2017). Geopolymers are also attracting attention for a variety of applications due to their excellent fire resistance, low cure temperature, low air and water permeability, durability and low processing costs.

Corresponding Author: Seunggu Kang, Department of Advanced Materials-Science and Engineering, Kyonggi University, Suwon, 211-302, 221 Seolleung-ro, Gangnam-gu, Seoul, Republic of Korea 
Meta-kaolin in particular has been extensively studied as a pure raw material, rather than wastes for geopolymers. In general, the compressive strength of meta-kaolin-based-geopolymers is known to be about 60 MPa (Mo et al., 2014).

The compressive strength of geopolymers varies greatly depending on the curing temperature and curing time (Jeon and Song, 2011). T. Bakharew reported a so-called 'pre-curing' process wherein a green geopolymer is left to stand at room temperature before the high-temperature curing process (Kim and Kang, 2014; Bakharev, 2005; Byeongguk et al., 2017). In this study, we have conducted experiments on and analyzed the change of compressive strength of a meta-kaolin-based-geopolymer as a function of the conditions for the pre-curing process.

\section{MATERIALS AND METHODS}

Experimental: The raw materials for the production of the geopolymer were meta-kaolin supplied by ' $\mathrm{N}$ ' company and sodium hydroxide (duksan, extra pure grade, $93-100 \%$ ) was used as the alkali activator to activate the geopolymer reaction. The alkali activating solution was prepared by mixing sodium hydroxide and distilled water at $15 \mathrm{M}(\mathrm{mol} / \mathrm{L})$. Prior to this experiment, a preliminary experiment was conducted to fix the water/solid ratio (W/S ratio, weight basis) using the batch as shown in Table 1. The alkali activating solution was mixed with meta-kaolin for $15 \mathrm{~min}$ in a bowl and then the mixture was cured in a brass, cube-shaped mold $\left(5 \times 5 \times 5 \mathrm{~cm}^{3}\right)$. The prepared specimens were sealed in a polyethylene zipper bag to prevent crack formation due to rapid water evaporation during high temperature curing. The curing schedule is shown in Table 1 . The specimen name shows pre-curing time, curing time and aging time. For example, the ' $0 / 1 / 2$ ' specimen indicates that it was fabricated by the pre-curing process for 0 day, curing process for 1 day and aging process for 2 days. The temperature for each curing process is 23,70 and $23^{\circ} \mathrm{C}$ for pre-curing, curing and aging process, respectively. A flow chart illustrating the geopolymer fabrication process is shown in Fig. 1.

The chemical composition and crystal phase of meta-kaolin were analyzed using XRF (X-ray Fluorescence, Spectro 2000) and XRD (X-ray Diffractometer, MiniFlex 2, Rigaku, Japan), respectively. The setting time in other words, hardening time, of the geopolymer paste was measured by using Gilmore's needle based on "KS L 5103", one of the cement setting time test methods. By measuring the setting time of the geopolymer, the relative curing rate at each temperature was obtained. The compressive strength of the prepared
Table 1: Details of curing process for geopolymer fabrication Specimen Total process Pre-curing time Curing time Aging time ID time (days) at $23^{\circ} \mathrm{C}$ (days) at $70^{\circ} \mathrm{C}$ (days) at $23^{\circ} \mathrm{C}$ (days) $\begin{array}{lllll}0 / 1 / 2 & 3 & 0 & 1 & 2\end{array}$ $\begin{array}{llll}1 / 1 / 1 & 1 & 1 & 1 \\ 2 / 1 / 0 & 2 & 1\end{array}$ $2 / 1 / 0 \quad 2 \quad 110$ $\begin{array}{lllll}0 / 1 / 6 & 7 & 0 & 1 & 6 \\ 1 / 1 / 5 & & 1 & 1 & 5\end{array}$ $\begin{array}{llll}2 / 1 / 4 & 2 & 1 & 4\end{array}$ $3 / 1 / 3 \quad 3 \quad 113$

$4 / 1 / 2 \quad 4 \quad 112$

$5 / 1 / 1$

$6 / 1 / 0$

$0 / 1 / 27$

$6 / 1 / 21$

$10 / 1 / 17$

$13 / 1 / 14$

$17 / 1 / 10$

$20 / 1 / 7$ $27 / 1 / 0$ 28

$\begin{array}{lll}5 & 1 & 1 \\ 6 & 1 & 0\end{array}$
27
21 21 17
10 10 7

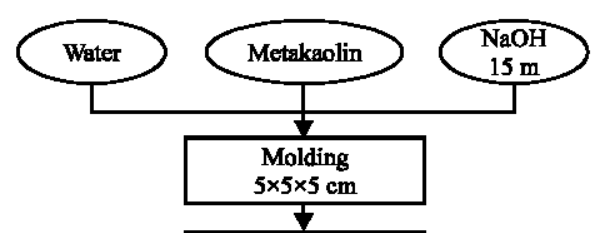

Sealing in plastic bag
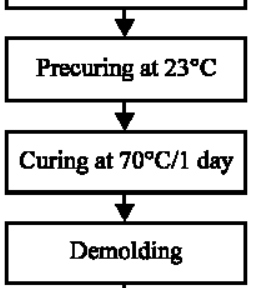

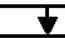

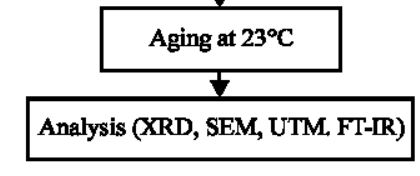

Fig. 1: Flow chart of geopolymer fabrication process using meta-kaolin

geopolymer samples was measured by a UTM (Universal Testing Machine) and the binding structure was analyzed using FT-IR (Fourier Transform-Infrared spectroscopy; TENSOR27, Bruker, Germany). The phase and the morphology of the geopolymers were analyzed by XRD (X-ray Diffractometer, Mini-Flex II, Rigaku, Japan) and SEM (Scanning Electron Microscope; S-4800, Hitachi, Japan), respectively.

\section{RESULTS AND DISCUSSION}

Effect of W/S ratio and setting time: The chemical composition and the crystal phase of meta-kaolin were analyzed using $\mathrm{XRF}$ and $\mathrm{XRD}$, respectively and are shown in Table 2 and Fig. 2. The total content of $\mathrm{SiO}_{2}$ and 


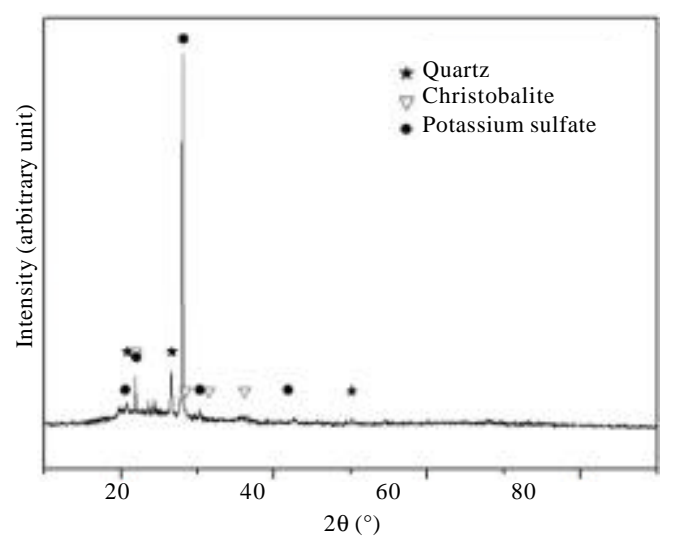

Fig. 2: XRD pattern of meta-kaolin, starting raw material for geopolymer fabrication

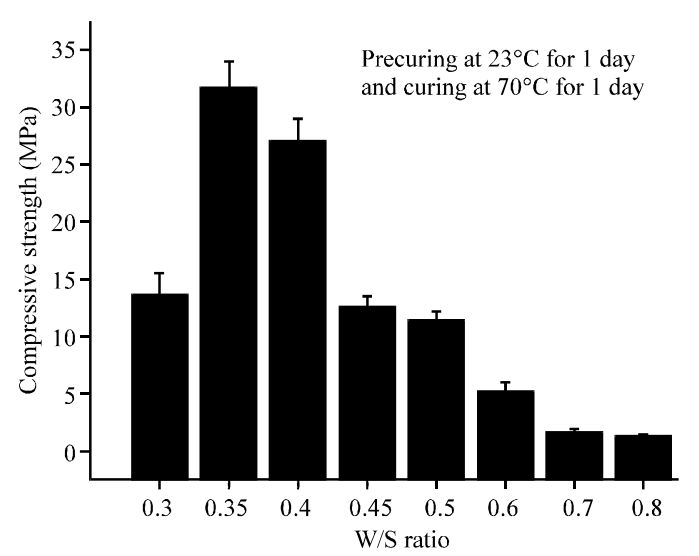

Fig. 3: Compressive strength of geopolymers made with various (W/S ratios)

Table 2: Chemical compositions of meta-kaolin determined by XRF (wt.\%) \begin{tabular}{llllllllll}
$\mathrm{SiO}_{2}$ & $\mathrm{Al}_{2} \mathrm{O}_{3}$ & $\mathrm{Na}_{2} \mathrm{O}$ & $\mathrm{CaO}$ & $\mathrm{Fe}_{2} \mathrm{O}_{3}$ & $\mathrm{MgO}$ & $\mathrm{K}_{2} \mathrm{O}$ & $\mathrm{TiO}_{2}$ & $\mathrm{IL}^{*}$ & Total \\
\hline
\end{tabular} \begin{tabular}{llllllllll}
50.8 & 38.5 & 0.5 & 1.6 & 3.7 & 0.4 & 0.6 & 0.3 & 3.6 & 100 \\
\hline
\end{tabular}

$* \mathbb{L}$ indicates the weight loss up on ignition ( $\mathrm{Si} / \mathrm{Al}$ ratio 2.24$)$

$\mathrm{Al}_{2} \mathrm{O}_{3}$ was as high as $89 \mathrm{wt} . \%$ and the $\mathrm{Si} / \mathrm{Al}$ ratio was 2.24 . Meta-kaolin used in this study contained quartz, cristobalite and potassium sulfate as confirmed by the $\mathrm{XRD}$ analysis.

In general, the geopolymer is synthesized by polymerizing $\mathrm{Si}^{4+}$ and $\mathrm{Al}^{3+}$ ions dissolved in the raw material. At this time, the $\mathrm{Na}^{+}$ions present in the added activator participate to form a network structure in the form of -Si-O-Al (Na)-O-Si-. This is finally converted to

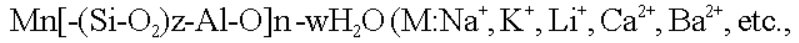
$\mathrm{Z}: 1 \sim 3, \mathrm{n}$ : polymerizability). In order to analyze the optimum W/S ratio, the specimens were prepared by varying the $\mathrm{W} / \mathrm{S}$ ratio in a range of $0.3 \sim 0.8$ and by pre-curing for 1 day during the total curing process for 2 days and the compressive strength was measured as shown in Fig. 3. Since, the highest compressive strength

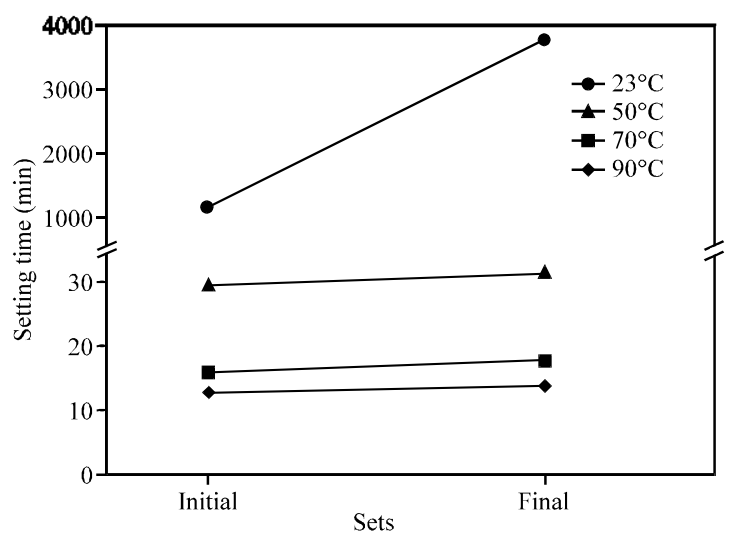

Fig. 4: Initial and final set time of meta-kaolin-basedgeopolymers with various curing temperatures

of $31.7 \mathrm{MPa}$ appeared when the W/S ratio was 0.35 , the $\mathrm{W} / \mathrm{S}$ for fabricating geopolymers was fixed at this value in the present study.

Since, the alkali polycondensation reaction of the geopolymer can be regarded as a dissolution-precipitation reaction, unlike the hydration reaction of general cement, the curing time of the geopolymer paste will be related to the elution and the reaction rate of the geopolymer component. The Gilmour needle test method measures two set times: the initial set time at which the fluidity of the geopolymer paste disappears and the final set time at which the mechanical strength begins to appear in the paste caused by increased or interlocking of the phases that occurred. Therefore, the reaction rate of various geopolymer samples can be indirectly evaluated using the Gilmour needle test (Jeon and Song, 2011).

According to B. Talling, a general geopolymer condensation reaction occurs at several stages: $\mathrm{Si}$ and $\mathrm{Al}$ ion elution reaction, the formation of precursors of $\mathrm{SiO}_{4}$ and $\mathrm{AlO}_{4}$ tetrahedra in the form of -Si-O-Si- and -Si-O-Aland a reaction that shares the oxygen atoms of the precursors and a forms three-dimensional structure by a polymerization reaction. Finally, the polymer is quantitatively increased and terminated by 3-dimensional polymerization (Talling, 1989). These reactions are not sequential but rather they proceed at the same time. Depending on the conditions, the reaction rate of each reaction is different, resulting in various properties (Duxson et al., 2007).

In order to evaluate the effect of temperature on the initial activation reaction rate between meta-kaolin and an alkali activating solution, the initial and final set time for pastes made with a W/S of 0.35 were measured using a Gilmoure needle at $23,50,70$ and $90^{\circ} \mathrm{C}$ as shown in Fig. 4. For the specimen measured at $23^{\circ} \mathrm{C}$, the initial set time was $1,200 \mathrm{~min}$ and the final set time was $3,780 \mathrm{~min}$, suggesting 


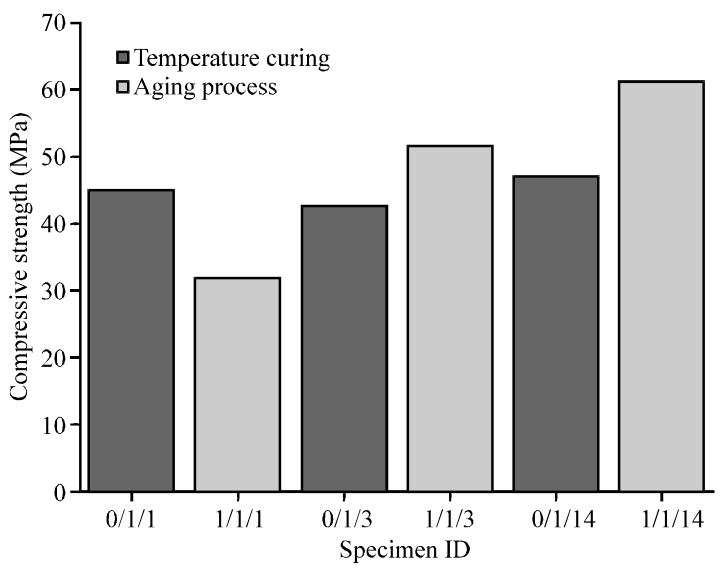

Fig. 5: Effect of pre-curing process upon compressive strength of geopolymers (W/S 0.35)

that the rate of the geopolymerization is too slow. On the other hand, for the measurement at $50^{\circ} \mathrm{C}$ or higher, all of the final set times were shortened, indicating that hardening of the geopolymer occurred in a shorter time. In particular for the measurement at $90^{\circ} \mathrm{C}$, the final set occurred $1 \mathrm{~min}$ after the time for the initial set was measured, indicating that the whole geopolymerization reaction proceeded very rapidly.

Effect of pre-curing process: The Gilmoure needle test showed that the condensation polymerization of meta-kaolin proceeded slowly at $23^{\circ} \mathrm{C}$, allowing sufficient time to elute $\mathrm{Si}$ and $\mathrm{Al}$ from meta-kaolin and to form the tetrahedral precursor. When the geopolymer was then cured at $70^{\circ} \mathrm{C}$, the sufficiently formed precursors bonded to each other to form a rigid three-dimensional polymer structure which is effective for high strength revelation. Accordingly, the geopolymers fabricated by the pre-curing process at $23^{\circ} \mathrm{C}$ followed by a high temperature curing process at $70^{\circ} \mathrm{C}$ showed enhanced compressive strength.

Figuer 5 shows the effect of the pre-curing process upon the compressive strength of the geopolymers. When only high-temperature curing and aging process were applied, the reaction is terminated in a short time and as a result the long-term compressive strength was not further increased. However, for the specimens made with the pre-curing process, the compressive strength increased with aging time. Therefore, it is considered that the pre-curing process enhances the long term strength of the geopolymers. However, for the results shown in Fig. 5, it is difficult to determine whether the strength enhancement is due to the pre-curing process or the increase of the total process time. Therefore, it is

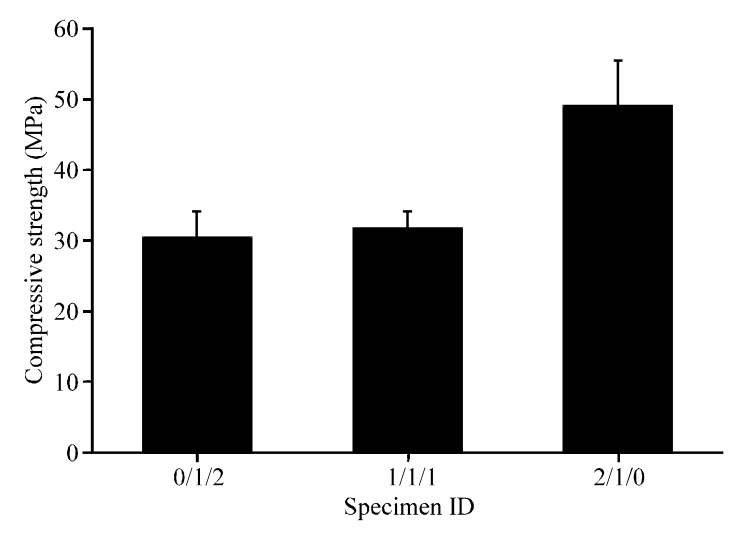

Fig. 6: Compressive strength of geopolymers made with various pre-curing times during the whole curing process of 3 days (W/S 0.35)

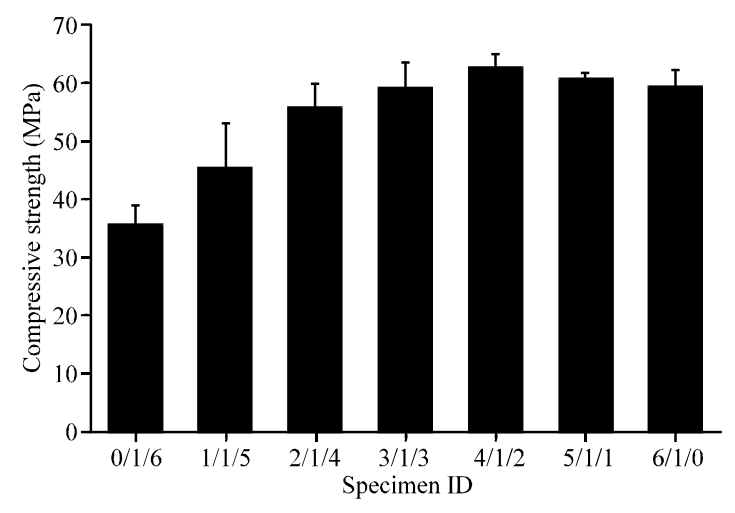

Fig. 7: Compressive strength of geopolymers made with various pre-curing times during the whole curing process of 7 days (W/S 0.35)

necessary to equalize the total processing time for all specimens, including pre-curing, curing and aging processes.

Figuer 6 shows the compressive strength of the specimen made with various pre-curing times during the whole curing process for 3 days. The specimens made with 2 days pre-curing showed a compressive strength of 48.7 $\mathrm{MPa}$ which is $160 \%$ higher than that (30.5 MPa) obtained for the specimen made with no pre-curing process. The compressive strengths of specimens made with various pre-curing times during the whole curing process for 7 and 28 days are shown in Fig. 7 and Fig. 8, respectively. The compressive strength of the specimens without pre-curing process during the whole curing process for 7 days was low at $35.6 \mathrm{MPa}$ as shown in Fig. 7. As the pre-curing time increases, however, the compressive strength increases, and the maximum value of 62.5 Mpa was exhibited for the 4/1/2 specimen. The 


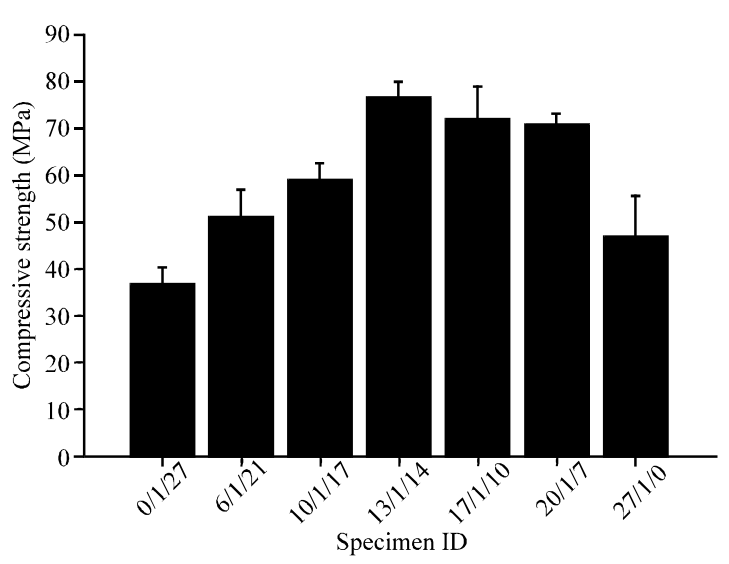

Fig. 8: Compressive strength of geopolymers made with various pre-curing times during the whole curing process of 28 days (W/S 0.35 ) highest compressive strength of 76.3 MPa was exhibited for the $13 / 1 / 14$ specimens which were made with the pre-curing process for 13 days during the whole curing process of 28 days as shown in Fig. 8.

This indicates that the elution of $\mathrm{Si}$ and $\mathrm{Al}$ ions from the raw material and the generation of $\mathrm{Si}-\mathrm{O}-\mathrm{Al}$ monomer proceeded sufficiently in the pre-curing process. As a result, a polymer with a three-dimensional structure is considered to be more effectively produced (Cho et al., 2014; Kim et al., 2010).

The XRD analysis results for specimens made with a total process time of 7 days are shown in Fig. 9. The 0/1/6 specimen was similar to the raw material shown in Fig. 2. That is, the geopolymer reaction did not sufficiently occur. However, the peak intensity of potassium sulfate $\left(\mathrm{K}_{2} \mathrm{SO}_{4}\right)$ decreased sharply as the pre-curing time increased. The peak of quartz did not change

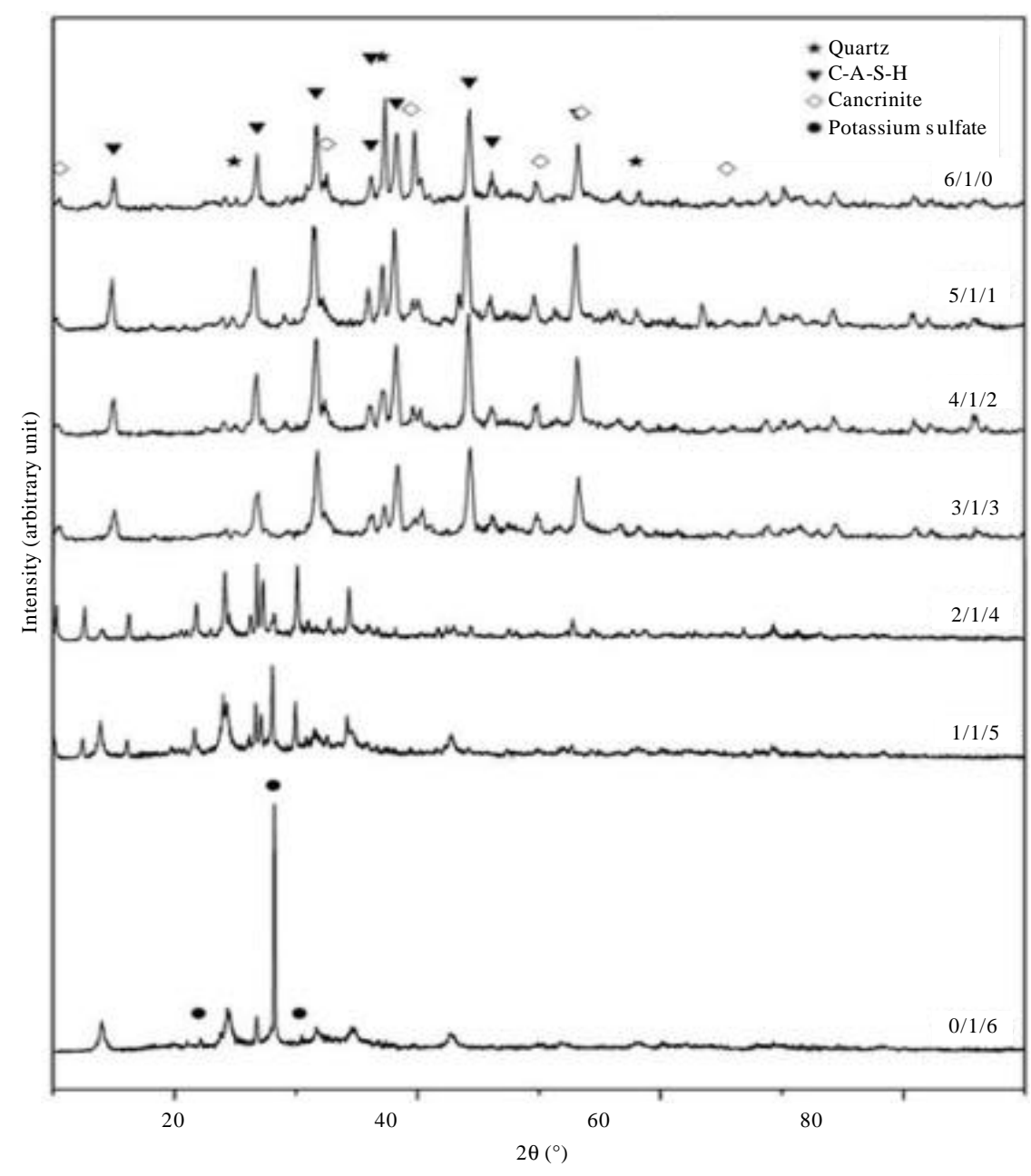

Fig. 9: XRD pattern of meta-kaolin-based-geopolymer prepared with various pre-curing times during the whole curing process of 7 days 


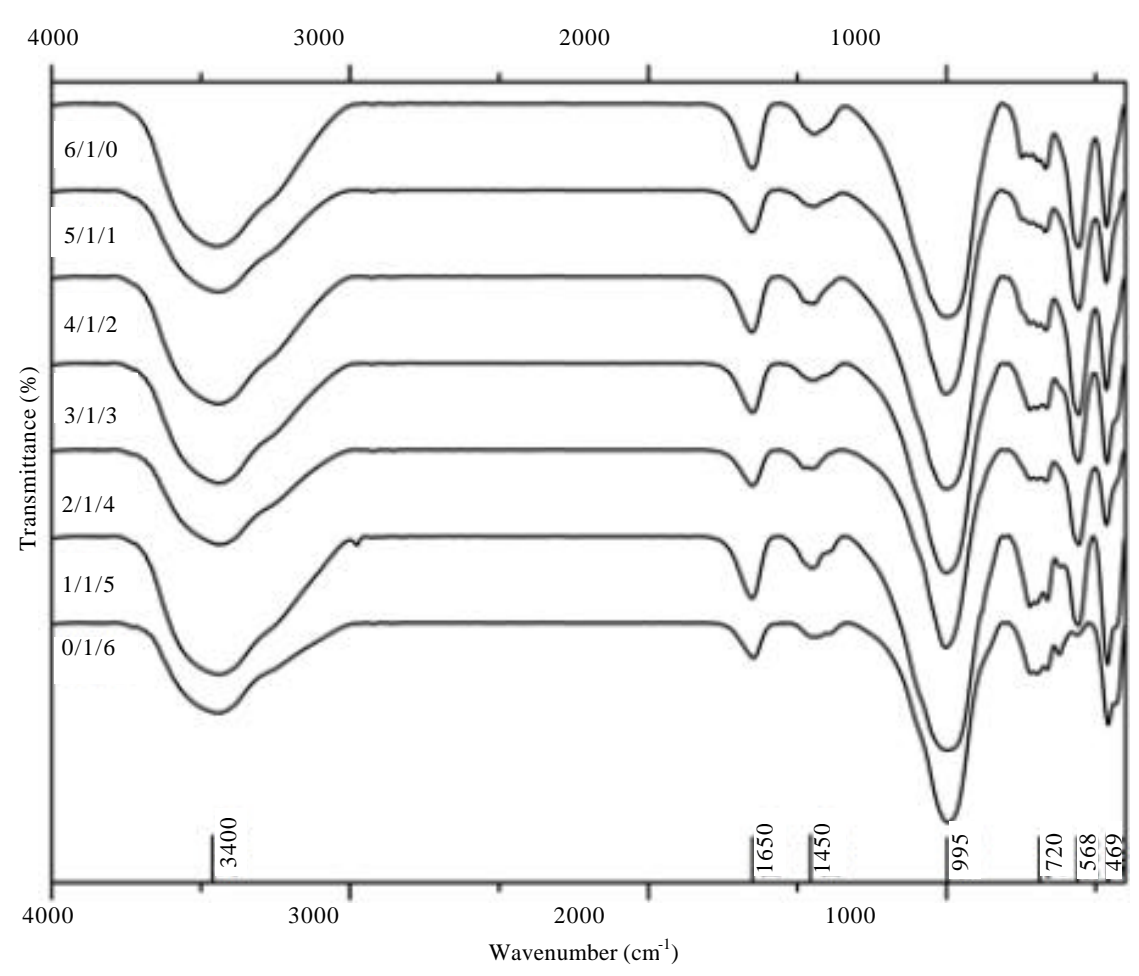

Fig. 10: FT-IR spectra of meta-kaolin-based-geopolymer prepared with various pre-curing times during the whole curing process of 7 days

substantially as the pre-curing time increased but when the pre-curing time was more than 3 days, peaks of the cancrinite $\left(\mathrm{Na}_{6} \mathrm{Ca}_{2}\left[\left(\mathrm{CO}_{3}\right)_{2} \mathrm{Al}_{6} \mathrm{Si}_{6} \mathrm{O}_{24}\right] \cdot 2 \mathrm{H}_{2} \mathrm{O}\right)$ phase, a type of zeolite crystal and a peak of $\left(\mathrm{Ca}_{6}\left(\mathrm{AlSiO}_{4}\right)_{12} \cdot 30 \mathrm{H}_{2} \mathrm{O}\right)$, a calcium silicate hydrate phase, appeared. However, for the specimen made with pre-curing time of 6 days $(6 / 1 / 0)$, the two zeolite crystals peaks again decreased. These XRD results are consistent with the compressive strength data shown in Fig. 7, the zeolite crystals are considered to positively affect the strength. In particular, the Calcium Aluminum Silicate Hydrate (hereinafter referred to as C-A-S-H) phase is consistent with Mobasher's result of enhanced compressive strength by C-A-S-H acting as a binder (Mobasher et al., 2016).

Figuer 10 shows the FT-IR analysis results for the specimens made with a total process time of 7 days. The broad absorption peak observed at around $3,400 \mathrm{~cm}^{-1}$ was due to the vibration of the $\mathrm{H}-\mathrm{O}-\mathrm{H}$ or $\mathrm{Si}-\mathrm{OH}$ bond and the peak at $1,647 \mathrm{~cm}^{-1}$ was due to the $\mathrm{Si}-\mathrm{OH}$ bond which is judged to be caused by the addition of an alkali activator. The peak at $469 \mathrm{~cm}^{-1}$ is the absorption peak caused by oscillation of the Si-O bond (Aredes et al., 2015). The absorption peaks that appeared at $1,100 \sim 940 \mathrm{~cm}^{-1}$ and $700 \sim 800560 \mathrm{~cm}^{-1}$ are known to be due to the vibration of a $\mathrm{Si}-\mathrm{O}-\mathrm{T}(\mathrm{T}=\mathrm{Si}$ or $\mathrm{Al})$ bond which is generated by condensation and polymerization of the geopolymer precursor (Part et al., 2015; Catauro et al., 2014). The peak at $560 \mathrm{~cm}^{-1}$ corresponds to the oscillation of double rings (D6R and D4R) in the zeolite A structure (Buchwald et al., 2011).

The spectrum in the range of $1400-1450 \mathrm{~cm}^{-1}$ is considered to be the absorption band representing the $\mathrm{CO}_{3}$ group, especially the $\mathrm{CaCO}_{3}$ and $\mathrm{Na}_{2} \mathrm{CO}_{3}$ bond structure (Somna and Bumrongjaroen, 2011; Linares et al., 2004). According to Li's study when N-A-S-H and C-A-S-H coexist, N-A-S-H is considered to be more unstable and is converted to the relatively stable C-A-S-H form (Li et al., 2016). Therefore, cancrinite $\left(\mathrm{Na}_{6} \mathrm{Ca}_{2}\left[\left(\mathrm{CO}_{3}\right)_{2} \mathrm{Al}_{6} \mathrm{Si}_{6} \mathrm{O}_{24}\right] \cdot 2 \mathrm{H}_{2} \mathrm{O}\right)$ was converted to calcium aluminium silicate hydrate $\left(\mathrm{Ca}_{6}\left(\mathrm{AlSiO}_{4}\right)_{12} \cdot 30 \mathrm{H}_{2} \mathrm{O}\right)$.

The microstructure of the specimen made with a total process time of 7 days is shown in Fig. 10. In the 0/1/6 specimen, most of the matrix is composed of geopolymer gel and smooth sections of the fractured surface are thought to be unreacted metakaolin (Catauro et al., 2014; Zhang et al., 2017). Unreacted metakaolin particles are cause of the low compressive strength of the geopolymer where the zeolite-A phase was observed in a plate-like form (Li et al., 2016; Zhang et al., 2017; Robayo-Salazar et al., 2016; Schumann et al., 2012). 
Taking the results of the microstructure and compressive strength into consideration together, it can be concluded that as the pre-curing period becomes longer, the number of unreacted meta-kaolin particles decreases and the matrix becomes denser, indicating that the pre-curing process increased the compressive strength of geopolymers.

\section{CONCLUSION}

This study investigated the effect of a pre-curing process on the compressive strength of meta-kaolinbased-geopolymers. Changes in the curing conditions change the rate of polymerization of the geopolymer and result in changes in physical properties.

The setting time was measured with a Gilmour needle test to determine the geopolymerization rate with temperature. The initial and final set time for the geopolymer measured at $23^{\circ} \mathrm{C}$ were 1,200 and $3,780 \mathrm{~min}$, respectively. For the specimen measured at $70^{\circ} \mathrm{C}$, the initial and final set time were 16 and $18 \mathrm{~min}$, respectively. The pre-curing process at $23^{\circ} \mathrm{C}$ allows elution of enough $\mathrm{Si}^{4+}$ and $\mathrm{Al}^{3+}$ ions from the raw materials and the amount of the tetrahedral precursor is increased. The precursor can then be condensed and polymerized via. a curing process at $70^{\circ} \mathrm{C}$. Therefore, the pre-curing process is considered to increase the compressive strength of the geopolymers. The specimen made with extremely long pre-curing time of 13 days among the total process time of 28 days showed the highest compressive strength, 76.3 $\mathrm{MPa}$. As the pre-curing process time increased, the crystal peaks of cancrinite of the zeolite structure and Calcium-Aluminum-Silicate-Hydrate (C-A-S-H) shown in the XRD pattern for the geopolymer increased. The presence of C-A-S-H and zeolite phases is accordingly thought to play a role in increasing the strength of the geopolymers.

\section{ACKNOWLEDGEMENTS}

This research was supported by the New and Renewable Energy Core Technology Program of the Korea Institute of Energy Technology Evaluation and Planning (KETEP), granted financial resource from the Ministry of Trade, Industry and Energy, Republic of Korea. (No. 20153030050080). This research was supported by Kyonggi University's Graduate Research Assistantship 2018.

\section{REFERENCES}

Anonymous, 2002a. $\mathrm{CO}_{2}$ emissions from fuel combustion. International Energy Agency, Paris, France.
Anonymous, 2002a. Kyoto protocol. United Nations Env ironment Programme, Nairobi, Kenya.

Aredes, F.G.M., T.M.B. Campos, J.P.B. Machado, K.K. Sakane and G.P. Thim et al., 2015. Effect of cure temperature on the formation of Metakaolinite-based geopolymer. Ceram. Intl., 41: 7302-7311.

Bakharev, T., 2005. Geopolymeric materials prepared using Class F fly ash and elevated temperature curing. Cem. Concr. Res., 35: 1224-1232.

Bhavana, V., 2015. Data security in cloud environments. AsiaPac. J. Convergent Res. Interchange, 1: 2508-9080.

Buchwald, A., H.D. Zellmann and C. Kaps, 2011. Condensation of aluminosilicate Gels-model system for geopolymer binders. J. NonCryst. Solids, 357: 1376-1382.

Byeongguk, K., K. Seunggu and K. Kangduk, 2017. A study on the enhancement of mechanical properties of Metakaolin-based-geopolymers using by precuring process. Intl. J. BioSci. Bio Technol., 9: 13-18.

Catauro, M., F. Bollino, F. Papale and G. Lamanna, 2014. Investigation of the sample preparation and curing treatment effects on mechanical properties and bioactivity of silica rich metakaolin geopolymer. Mater. Sci. Eng. C., 36: 20-24.

Cho, Y.K., G.D. Moon, J.M. La and S.H. Jung, 2014. Effect of curing conditions on the strength of Fly-ash based geopolymer. J. Korea Concr. Inst., 26: 449-456.

Choi, I.J., J.H. Kim and S.Y. Lee, 2016. Evaluation on reactivity of By-product pozzolanic materials using electrical conductivity measurement. J. Korea Inst. Build. Constr., 16: 421-428.

Davidovits, J., 1989. Geopolymers and geopolymeric materials. J. Therm. Anal. Calorim., 35: 429-441.

Davidovits, J., 1991. Geopolymers: Inorganic polymeric new materials. J. Thermal Anal., 37: 1633-1656.

Davidovits, J., 1994. Global warming impact on the cement and aggregates industries. World Resour. Rev., 6: 263-278.

Dubey, D. and G.S. Tomar, 2017. Echelon based pose generalization of facial images approaches. Asia Pac. J. Convergent Res. Interchange, 3: 63-75.

Duxson, P., A. Fernandez-Jimenez, J.L. Provis, G.C. Lukey and A. Palomo et al., 2007. Geopolymer technology: The current state of the art. J. Mater. Sci., 42: 2917-2933.

Jeon, C.S. and T.W. Song, 2011. Effect of curing temperature on geopolymeric polycondensation of blast furnace slag. J. Korean Ceram. Soc., 48: 610-616. 
Joo, G.T., T.K. Lee, M. Park and Y. Hwang, 2012. Compressive strength of geopolymers while varying the raw materials. J. Korean Ceram. Soc., 49: 575-580.

Kim, J.T., D.S. Seo, G.J. Kim and J.K. Lee, 2010. Influence of alkaline-activator content on the compressive strength of Aluminosilicate-based geopolymer. J. Korean Ceram. Soc., 47: 216-222.

Kim, Y. and S. Kang, 2014. Effect of thermal treatment on the Nano-structure and phase transformation of Metakaolin-based geopolymers. J. Nanosci. Nanotechnol., 14: 8902-8906.

Li, Z., T. Ohnuki and K. Ikeda, 2016. Development of paper sludge Ash-based geopolymer and application to treatment of hazardous water contaminated with radioisotopes. Mater., 9: 633-650.

Linares, C.F., S. Solano and G. Infante, 2004. The influence of hydrotalcite and Cancrinite-type zeolite in acidic aspirin solutions. Microporous Mesoporous Mater., 74: 105-110.

Mo, B.H., H. Zhu, X.M. Cui, Y. He and S.Y. Gong, 2014. Effect of curing temperature on geopolymerization of Metakaolin-based geopolymers. Appl. Clay Sci., 99: 144-148.

Mobasher, N., S.A. Bernal and J.L. Provis, 2016. Structural evolution of an alkali sulfate activated slag cement. J. Nucl. Mater., 468: 97-104.

Mounica, D., 2015. Risk assessment of information system. AsiaPac. J. Convergent Res. Interchange, 1: $31-40$.
Nadella, B., 2016. Data encryption using geometric range. Asia Pacific J. Convergent Res. Interchange, 2: 21-28.

Part, W.K., M. Ramli and C.B. Cheah, 2015. An overview on the influence of various factors on the properties of geopolymer concrete derived from industrial By-products. Constr. Build. Mater., 77: 370-395.

Pullagujju, G.K., 2015. Risk utilization in quantitative approach. Asia Pac. J. Convergent Res. Interchange, 1: 21-27.

Robayo-Salazar, R.A., D.R.M. Gutierrez and F. Puertas, 2016. Effect of metakaolin on natural volcanic Pozzolan-based geopolymer cement. Appl. Clay Sci., 132: 491-497.

Schumann, K., B. Unger, A. Brandt and F. Scheffler, 2012. Investigation on the pore structure of binderless zeolite $13 \times$ shapes. Microporous Mesoporous Mater., 154: 119-123.

Somna, K. and W. Bumrongjaroen, 2011. Effect of external and internal calcium in fly ash on geopolymer formation. Dev. Strategic Mater. Comput. Des. II Ceram. Eng. Sci. Proc., 32: 1-16.

Talling, B., 1989. Effect of curing conditions on Alkali-activated slags. Special Publ., 114: 1485-1500.

Zhang, F., L. Zhang, M. Liu, C. Mu and Y.N. Liang et al., 2017. Role of Alkali Cation in compressive strength of Metakaolin based geopolymers. Ceram. Intl., 43: 3811-3817.

Zhao, Q., B. Nair, T. Rahimian and P. Balaguru, 2017. Novel geopolymer based composites with enhanced ductility. J. Mater. Sci., 42: 3131-3137. 